\title{
Lettuce (Lactuca sativa) Production in Northern Latitudinal Aquaponic Growing Conditions
}

\author{
Marie Abbey and Neil O. Anderson \\ Department of Horticultural Science, University of Minnesota, 286 Alderman \\ Hall, 1970 Folwell Avenue, St. Paul, MN 55108
}

\author{
Chengyan Yue \\ Department of Applied Economics and Department of Horticultural Science, \\ University of Minnesota, 458 Alderman Hall, 1970 Folwell Avenue, St. Paul, \\ MN 55108
}

\section{Michele Schermann \\ Department of Horticultural Science, University of Minnesota, 286 Alderman Hall, 1970 Folwell Avenue, St. Paul, MN 55108}

\author{
Nicholas Phelps and Paul Venturelli \\ Department of Fisheries, Wildlife and Conservation Biology, University of \\ Minnesota, 135 Skok Hall, 2003 Upper Buford Circle, Suite 135, St. Paul, \\ MN 55108
}

\section{Zata Vickers}

Department of Food Science and Nutrition, University of Minnesota, 1334 Eckles Avenue, St. Paul, MN 55108

Additional index words. Carassius auratus (goldfish), Cyprinus carpio (koi), deep water culture, ebb and flow, Oreochromis spp. (tilapia), Perca flavescens (yellow perch)

\begin{abstract}
Aquaponics, the combination of hydroponics and aquaculture into one growing system, is a controlled environment production system that potentially has increased environmental and consumer benefits over traditional production methods. There are many different ways to configure aquaponics systems that include different fish species, water circulation, lighting, plant species/density, and more. We tested three cultivars of lettuce, a common aquaponically produced crop, for yield in multiple aquaponic systems and conditions over a 13-month period in Minnesota. Four different aquaponic configurations and four types of fish were tested over the course of the experiment. There was no addition of supplemental nutrients to the systems to evaluate the differences between treatments and set a baseline. There was no difference in yield between lettuce produced aquaponically and those grown in soilless medium. However, there was a difference in yield between lettuce grown with different fish treatments. The tilapia treatment produced higher average yield than yellow perch. There was a difference between cultivars, with higher average yield from loose-leaf bunch cultivars (Salanova, Skyphos) than the bibb type (Rex). Average yield for all but one treatment was above that of reported commercial field production, making lettuce a competitive aquaponic crop in most systems.
\end{abstract}

Aquaponics incorporates hydroponics (soilless plant production) and aquaculture (fish production) into a closed-loop, recirculating system (Rakocy et al., 2006). Waste from the fish production provides the primary nutrients for the crop plants, the root systems of which provide a natural filter for the water recircu-

\footnotetext{
Received for publication 5 Apr. 2019. Accepted for publication 28 June 2019

This research was supported, in part, by a grant from the University of Minnesota Global Food Ventures MNDrive and the Minnesota Agricultural Experiment Station.

N.O.A. is the corresponding author. E-mail: ander044@ umn.edu.
}

lated to the fish (Rakocy et al., 2006). Thus, fish food becomes the only nutritional input (nutrients) into any aquaponic system. Nutrient cycling consists of fish waste (ammonia, urea) converted by nitrifying bacteria in a biofilter into a form of $\mathrm{N}$ (nitrate $\mathrm{N}$ ) that can be taken up by plant roots (Diver and Rinehart, 2006).

Aquaponics was developed as a means to control wastewater from recirculating aquaculture systems (RAS) (Costa-Pierce et al., 1997). Although RAS have many benefits, water conservation is not one of them, and there was a demand to develop a costeffective filtration system. Plants can be used as filters for RAS wastewater and as a secondary crop that led to the development of closed-loop aquaponic systems (Lewis,
1978; Rakocy et al., 2006). There was also a motivation from hydroponic growers to develop cost-effective and environmentally friendly nutrient solution sources (Rakocy et al., 2007).

Aquaponic production is a rapidly expanding agricultural sector (Kloas et al., 2015) owing to increased population growth, water scarcity, and increased water needs by agriculture (Hundley and Navarro, 2013). The projected aquaponic growth worldwide may surpass $10 \%$ by 2020 (Cision PR Newswire, 2016). Easily adaptable to urban agricultural production, aquaponics now has $>100$ million growers (Eigenbrod and Gruda, 2015).

Both for farm size and revenue stream, most aquaponic producers are in the small farm category (Love et al., 2014). Aquaponic systems have a wide range in scale, system design, plant crops, fish species, and management procedures. Each system type is specifically designed for the location, production goals, market demand, and production facility, such as controlled environment greenhouses or warehouses (Love et al., 2015). Deep water culture (DWC) is the most popular commercial aquaponic system in which fish and plants are physically separated but coupled together; the plants grow on floating rafts with the roots growing in the nutrient-rich water after processing in the biofilter (Taiz and Zeiger, 2010).

Other types of commercial systems include ebb and flow systems in which the plant roots are intermittently submerged in water, although it is less common than DWC. Aeroponic and nutrient film techniques are not as commonly used in aquaponic production because of solids clogging the system (Søberg, 2016)

In Minnesota and the north central region of the United States, aquaponics is of interest to greenhouse and warehouse producers, with numerous aquaponic facilities in operation around the state and area. We previously examined consumer perceptions and awareness of aquaponic-grown products (Short et al., 2018). Only a third of the consumers surveyed knew of aquaponics; their general attitude was neutral or favorable toward it. Although aquaponics was viewed as environmentally favorable, price could be an issue for consumers and, thus, education and marketing would be critical for future market success (Short et al., 2018).

Commonly grown crops in aquaponics are lettuce and basil (Love et al., 2014). A recent study found that aquaponic-grown, day-neutral strawberries in greenhouses and warehouses could be produced year-round (Abbey et al., 2019). However, there were several production issues that needed careful management to have yields comparable to hydroponic greenhouse or field-grown types.

Lettuce, Lactuca sativa, is the most commonly grown leafy green in commercial aquaponics systems (Lennard and Leonard, 2004; Pantanella et al., 2012). There are several reasons lettuce is popular among aquaponics growers: it is an annual plant 
(fast production time from seed to leaf or head harvest), has a long cultivation history $(<4500 \mathrm{BC})$ with numerous market types (morphological forms) and cultivars available, as well as having a shallow, fibrous root system adaptable to hydroponic and aquaponic production systems (Welbaum, 2015). Lettuce also does not require the addition of pollinators that would need to be provided in controlled environment production such as aquaponics.

The four most common morphological forms of lettuce are loose-leaf, crisphead, butterhead, and romaine (Doležalová et al., 2004). These were described as early as 1586 by Joachim Camerarius (Kuete, 2017), and three of these types were brought to the Americas by Christopher Columbus. Crisphead lettuces are more commonly known as 'Iceberg' or head lettuce. 'Iceberg' was bred by Washington Atlee Burpee, the founder of Burpee Seed Company (Warminster, PA), and has been on the market since 1894 (Burpee Seed Co., n.d.). This type is not commonly grown in aquaponic systems because the individual heads at harvest can weigh 0.7 to $1.0 \mathrm{~kg}$ each (Welbaum, 2015), and floating rafts would sink from the weight of multiple lettuce heads. Romaine or cos types also form heads but they are elongated rather than spherical (as with 'Iceberg' and butterhead types) and the leaves have large midveins; the weight of the heads means this type also is not feasible for floating raft hydroponic systems. Butterhead lettuce also forms a head with tender leaves, compared with 'Iceberg'; it is suited only for short-distance shipping (Welbaum, 2015) but can be grown in aquaponics because of its reduced weight. Loose-leaf (bunching) types can mature as fast as 4 weeks after transplanting (Welbaum, 2015). These are the most commonly grown type in aquaponics because of reduced weight and either single or multicut harvests.

Lettuce prices in 2018 rose $52 \%$ in the United States over the previous year (Parr et al., 2018). In the United States, 98\% of lettuce is produced in California and Arizona and most is produced as a field crop (U.S. Department of Agriculture, National Agricultural Statistics Service, 2017). Lettuce is both the most consumed fresh vegetable in the United States (Agricultural Marketing Resource Center, 2018) and the most popular leafy greens crop of aquaponic producers (Love et al., 2014). Lettuce is classified commercially into two different types: crisphead, which makes up $51 \%$ of consumption, and loose-leaf (including romaine and bibb types), which constitutes the remainder (Agricultural Marketing Resource Center, 2018).

The objective of this study was to create a baseline for potential yield of lettuce in yearround aquaponic production systems in northern latitudes. Our hypotheses tested in this experiment include the following: $\mathrm{H}_{\mathrm{o}}$ : There is no difference in yield between lettuce produced aquaponically and lettuce grown in soilless medium. Furthermore, $\mathrm{H}_{\mathrm{o}}$ : There is no difference in yield between lettuce grown in different aquaponic treatments.

\section{Materials and Methods}

\section{Genotypes tested}

This experiment was conducted for a 13month period (Jan. 2016-Feb. 2017). Three cultivars of lettuce were used for this experiment: Rex, Skyphos, and the Salanova Series Mix. The mix is a composite mix of four different cultivars: Salanova Green Incised, Salanova Green Sweet Crisp, Salanova Red Incised, and Salanova Red Sweet Crisp. It is sold and treated in this experiment as one single cultivar, Salanova. Pelleted seed lots were acquired from Johnny's Selected Seeds (Fairfield, ME). Cultivars were chosen based on popularity in the fresh market and those grown in other aquaponic systems.

Lettuce seeds were sown in 288-plug trays filled with a soilless media, pasteurized Berger BM2 Germination Mix (Berger Peat Moss, Saint-Modeste, Quebec, Canada) or in 3.81-cm-diameter cylinder Trock rockwool plugs (medium grade, 4CF, 30/PL; Therm-ORock East, Inc., New Eagle, PA). For seed germination, a mist system in a glass greenhouse was used $\left(21 / 21{ }^{\circ} \mathrm{C}\right.$, day/night, $16 \mathrm{~h}$; 0600-2200 HR) lighting at a minimum setpoint of $150 \mu \mathrm{mol} \cdot \mathrm{m}^{-2} \cdot \mathrm{s}^{-1}$, a mist frequency of 10-min intervals (mist nozzles, reverse osmosis water) during 0600-2200 HR with a 7-s duration (Anderson et al., 2011). After seedlings were at the true leaf stage, the seedlings in rockwool plugs were transplanted into the aquaponic systems, whereas those in the germination mix were transplanted into a soilless medium. The aquaponics research was located in the Minneapolis-Saint Paul metropolitan area, Minnesota, specifically located at the St. Paul Campus of the University of Minnesota (lat. $44^{\circ} 59^{\prime} 17.8^{\prime \prime} \mathrm{N}$, long. $93^{\circ} 10^{\prime} 51.6^{\prime \prime}$ W).

Fish species grown in the various aquaponic production facilities consisted of the following: Perca flavescens (yellow perch), Oreochromis spp. (tilapia), Cyprinus carpio (koi), and Carassius auratus (goldfish). Goldfish were purchased at PetSmart (Roseville, MN) in Mar. 2014. The tilapia were obtained as fingerlings from Arrowhead Fisheries, LLC (Canon City, CO) in Jan. 2015. Yellow perch fingerlings were purchased from Will Allen Farms, Growing Power (Milwaukee, WI) in Mar. 2015. Koi were bought from Tangletown Gardens (Plato, MN) in Feb. 2016. Once the biofilters were established, the fish were acclimated and placed in each system.

\section{Experimental setup}

The experimental setup was identical to that used for aquaponic strawberry production (Abbey et al., 2019). Systems were established as equipment and space became available, which resulted in staggered start times for the systems. Environmental systems were the treatments and included the following: a) soilless medium (control), b) floating raft DWC, c) A-frame ebb and flow, d) tray ebb and flow, and e) warehouse. Treatments (a) through (d) were conducted in greenhouses, and (e) was in a warehouse. Treatments (c) and (e) used koi, treatment (b) used yellow perch, and treatment (d) used both goldfish and tilapia. All treatments were equally randomized throughout each system (Abbey et al., 2019). With the exception of the A-frame ebb and flow, all treatments had a randomized block design. The A-frame ebb and flow treatments were randomized by each $\mathrm{PVC}$ pipeline of plants (see Fig. 1 in Abbey et al., 2019). The number of experimental units also varied by treatment, with the exact number dependent on space availability. The soilless medium treatment had 32 plants per cultivar; the A-frame ebb and flow had 8 plants per tube for a total of 48 plants per A-frame; the tray ebb and flow had 9 plants per tub; the floating raft DWC systems had 4 plants per tank, and the warehouse had 30 plants per cultivar equally divided between the two growing tubs. In all systems, lettuce plants were grown alongside strawberry (Fragaria xananassa 'Albion', 'Portola', and 'Evie 2'; Abbey et al., 2019) and basil (Ocimum basilicum 'Nufar', 'Genovese', and 'Elenora'). Basil production will be analyzed in a separate paper.

\section{Environmental conditions}

Soilless medium (control). The greenhouse environmental conditions for lettuce production in soilless medium were $24.4 \pm$ $3.0 / 18.3 \pm 1.5^{\circ} \mathrm{C}$ day/night daily integral and a 16-h-long day photoperiod (0600-2200 HR) lighting (400-W high-pressure sodium highintensity discharge lamps, HPS-HID) at a minimum of $150 \mu \mathrm{mol} \cdot \mathrm{m}^{-2} \cdot \mathrm{s}^{-1}$ (Abbey et al., 2019) The greenhouse, located in the St. Paul campus Plant Growth Facilities (University of Minnesota, St. Paul, MN), construction components and computerization specifics have been previously published (Abbey et al., 2019). Electric generators served as the electrical power backup system for all aquaponic setups.

Lettuce seedlings (germination mix) were transplanted into square $754 \mathrm{~cm}^{3}$ plastic pots (Landmark Plastic, Akron, OH) filled with soilless potting medium (Sunshine LC8; Sun Gro Horticulture, Agawam, MA). Plants were fertilized twice daily, between $0700-0800$ and 1600-1700 HR, using a constant liquid feed of $125 \mathrm{ppm} \mathrm{N}$ from water-soluble $20 \mathrm{~N}-4.4 \mathrm{P}$ 16.6K (Scotts, Marysville, OH). Fungicide drenches were applied in monthly rotations, as previously described for aquaponic strawberries (Abbey et al., 2019).

Biocontrol methods used yellow sticky cards $(12.7 \times 7.6 \mathrm{~cm}$; Evergreen Growers Supply, Clackamas, OR) to catch flying insects. Various types of mites (Amblyseius andersoni, Amblyseius cucumeris, Amblyseius swirskii, Neoseiulus fallacis, Galendromus occidentalis, Neoseiulus californicus, Phytoseiulus persimilis; Beneficial Insectary, Redding, CA, and Rincon Vitova, Ventura, CA) were released rotationally for bio control in all greenhouses, as well as the warehouse over the course of the experiment for control of spider mites (Tetranychus urticae), white flies (Trialeuroides vaporariorum), and thrips (Thysanoptera spp.) (Abbey et al., 
2019). Cease fungicide (Bioworks Inc., Victor, NY) was applied weekly during Nov. 2016 to control powdery mildew (Podosphaera xanthii).

Floating rafts. This aquaponic greenhouse had a $23.6 \pm 0.8^{\circ} \mathrm{C}$ daily integral with a temperature set-point at $23.5^{\circ} \mathrm{C}$. The same photoperiod (long day) and biocontrol methods as instituted in the soilless medium treatment were repeated here. This system had eight aluminum tanks $(193.0 \times 77.5 \times$ $75.0 \mathrm{~cm}$, length $\times$ width $\times$ height with $6.5-\mathrm{cm}$ thick walls) for fish and plant production. Each tank had a floating raft system (2/tank; $60 \times 60 \times 5.5 \mathrm{~cm}$; Owens Corning FOAMULAR 150, R-10 insulation sheathing; Owens Corning Co., Toledo, $\mathrm{OH}$ ); the water volume in each tank was $\approx 550 \mathrm{~L}$ or $0.55 \mathrm{~m}^{3}$. Two plastic, hemispherical tanks $(68 \times 47 \times 26$ $\mathrm{cm})$ were connected to each fish tank and served as the biofilters. Each biofilter was filled with 2-cm-diameter granite gravel (Hedberg Aggregates, Stillwater, MN) and started with ammonium chloride $(1 \mathrm{~g} /$ biofilter; Hawkins Chemical Co., Roseville, MN). A low density ( $\approx 25-30$ fish/tank) of goldfish was used to start the biological filter in the gravel; these were later removed and replaced with yellow perch. Ammonium carbonate was used instead in the A-frame and tray ebb and flow systems to start the biofilter in 8- to 10-cm-diameter lava rock (D-Rock Center, New Brighton, MN) to produce $\approx 1 \mathrm{mg} / \mathrm{L}$ ammonia with an initial start of goldfish. Water was lifted to the biofilter tanks by a magnetic drive pump (Danner Supreme 700 GPH; Danner, Islandia, NY) The outflow had valves and was split between the two biofilter tanks and a third outlet that discharged directly to the fish tank for added aeration and circulation. Each biofilter received $\approx 4 \mathrm{~L} / \mathrm{min}$. An automatic bell siphon in each of the biofilter tanks allowed the water level to rise in the gravel from a low point of $\approx 2-\mathrm{cm}$ depth to a high of $\approx 15 \mathrm{~cm}$. At the high point, the siphon would start and the water would drain into the fish tank, creating an ebb and flow in the gravel. Potential plant spacing on each raft could be a maximum of 16 plants in a $4 \times 4$ grid, each plant could be grown in a $12-\mathrm{cm}$-diameter net cup (Hydrofarm Central, Grand Prairie, TX) filled with rockwool.

Water quality was monitored regularly (5/wk, excluding weekends; Abbey et al., 2019). Daily temperature was $22.3+0.9^{\circ} \mathrm{C}$. The fish species grown in this house and used for the duration of the experiment was yellow perch at varying densities (20-30 fish/tank), depending on age (Sorensen et al., 2015).

$A$-frame $e b b$ and flow. This greenhouse had a $21.7 \pm 0.4{ }^{\circ} \mathrm{C}$ daily integral with a temperature set-point of $21.5^{\circ} \mathrm{C}$ (Abbey et al., 2019). Daily temperatures were $23.5 \pm 0.9^{\circ} \mathrm{C}$. The same photoperiod (long days) and biocontrol methods were used as in the soilless medium treatment.

Two tanks in this greenhouse each feed separate A-frame ebb and flow systems (see Fig. 1 in Abbey et al., 2019). Fish species grown in this house were koi at varying densities, depending on fish age. Airlift pumps move the water from the fish tank to the biofilter; a Danner Supreme $700 \mathrm{GPH}$ mag drive pump lifted the water from the biofilter to the A-frame lines, draining back to the fish tank. Four plastic, hemi cylindrical tanks $(68 \times 47 \times 26 \mathrm{~cm})$, mounted below each A-frame, were filled with 3- to 4-cm-diameter lava rock and were the biofilters.

Tray ebb and flow. For this greenhouse, the daily integral was $21.7 \pm 0.4{ }^{\circ} \mathrm{C}$ with a temperature set-point of $21.5{ }^{\circ} \mathrm{C}$ (Abbey et al., 2019). Identical photoperiod (long days) and biocontrol methods were used herein as for the soilless medium.

One fish tank (aluminum; identical specifications as the floating raft, A-frames, ebb and flow systems) was used for each of the two independent galvanized steel frame, adjustable shelving rack system (ebb and flow systems). One fish tank had tilapia, which fed a separate biofilter and shelving rack systems, and goldfish were in the other tank, which also fed another identical system. All fish were at varying densities, depending on fish age.

Each system had two shelves per rack (see Fig. 2 in Abbey et al., 2019). Two tubs per shelf $(123 \times 94 \times 18 \mathrm{~cm}$; Polytank Co., Litchfield, MN), each of which could hold six $50.8 \times 25.4-\mathrm{cm}(10 \times 20$-inch $)$ trays into which separate plug trays (50s or $72 \mathrm{~s}$ ) were inserted to hold the plants. The top shelf of each rack system is exposed to natural and supplemental lighting (high-pressure sodium high-intensity discharge lights), whereas the second shelf has supplemental light-emitting diode (LED) lighting supplied by either Sunshine Systems GrowPan (450-470, 630 nm; 300 W; Sunshine Systems, LLC, Wheeling, IL) or Green Power LED (450-470, 660 $\mathrm{nm} ; 300 \mathrm{~W} ; 152 \times 12 \mathrm{~cm} ; 110$-V strips; Royal Philips N.V., Andover, MA). One plastic, rectangular tub $(123 \times 186 \times 18 \mathrm{~cm}$; Polytank Co., Litchfield, MN) served as a biofilter for each tank and was filled with 3- to 4-cmdiameter lava rock. The tubs were set on a concrete floor.

Warehouse. The warehouse system was a retrofitted walk-in cooler $(7.19 \times 4.87 \times$ $2.74 \mathrm{~m}$ ), in the basement of the Plant Growth Facilities headhouse, which had galvanized interior walls with an F5 (Fantastically Fun Fresh Food Factory) commercial-type system from Nelson and Pade Company (http:// aquaponics.com/; Montello, WI) installed. The F5 system consists of one 416-L fish tank with separate bio filters and two $0.9 \times$ $1.5-\mathrm{m}$ plastic tubs that hold floating rafts. There are $15,5.8-\mathrm{cm}$ net pots per raft and two rafts per tub for a total of 90 plants possible to be grown in this system. The LED lighting system used was a triple-band LED light (bar) above the plants, that could telescope vertically as plant height increased (Agrivolution LLC http://www.agrivolution.co/; South Windsor, CT). The LEDs had single-chip diodes emitting blue, green, and red light with full photosynthetically active radiation $(P A R=$ $400 \mathrm{~nm}$ to $700 \mathrm{~nm}$ ). Supplemental cooling was used to maintain average growing temperatures of 20 to $21{ }^{\circ} \mathrm{C}$ day/night.

\section{Data collection}

The lettuce plants were harvested every 4 weeks. All systems had at least six harvests. The entire plant was harvested by cutting at the top of the soilless media or rockwool plug to divide it into the marketable top half and the roots (bottom half). Harvested aboveground portions were weighed (fresh weight, g) and then placed in a high-temperature oven $\left(76.67^{\circ} \mathrm{C}\right)$ (Hotpack, Philadelphia, PA) for 7 d. Plants were then removed and weighed once more after drying was complete (dry weight, $g$ ).

\section{Statistical analyses}

A Generalized Linear Mixed Model test using non-normal distribution (GLIMMIX) was used to analyze the fresh and dry weights. The analysis was conducted using a split-plot design using the type of fish as the treatment and cultivars as the variable. The koi treatments in systems $\mathrm{C}$ and $\mathrm{E}$ were analyzed separately. The dependent variables in this analysis are fresh and dry weights.

The GLIMMIX determined the correlation between data that has been fit to a specified statistical model (Abbey, et al., 2019). Common non-normal distribution models were tested and the lognormal distribution was found to have the lowest Akaike Information Criterion and Bayesian Information Criterion, and therefore the best fit. GLIMMIX assumed a normal distribution of random effects, which fits this experiment. All tests were conducted using the software SAS v. 25 (StataCorp, Cary, NC).

\section{Results}

The lettuce fresh and dry weights were both significant at $P \leq 0.01$ or greater (Table 1) when compared by greenhouse location (both ebb and flow systems resided in the same greenhouse) and fish treatment (both including and excluding soilless medium). When cultivars were compared, there was also a significant $(P \leq 0.01$ or greater $)$ difference in fresh and dry weights (Table 1).

The mean lettuce weights, subdivided by location (including the soilless medium) and fish treatments, had a wide range in variation. The floating raft DWC, which had perch as the fish treatment, had the lowest mean fresh weight at $65.6 \mathrm{~g}$ (Table 2). The tilapia treatment had the highest fresh weight with $172.3 \mathrm{~g}$. The tray ebb and flow tilapia treatment had the highest mean dry weight $(8.16 \mathrm{~g})$, whereas the DWC perch treatment had the lowest ( $2.84 \mathrm{~g}$; Table 2 ). There was a large amount of variation within all treatments, as evidenced by the large SD, with one instance wherein the SD exceeded the mean (A-frame ebb and flow, koi fresh weights; Table 2).

There was a significant difference among lettuce cultivars for all measured factors. 'Skyphos' had higher fresh weight, with an average weight of $123.2 \mathrm{~g}$, than 'Rex', with an average fresh weight of $94.8 \mathrm{~g}$ (Table 3 ). However, 'Rex' had a higher mean dry weight with $6.25 \mathrm{~g}$ than either 'Skyphos' 
Table 1. Significance levels (analysis of variance) of fresh weight (g) and dry weight (g) of total lettuce yield from aquaponic treatments by greenhouse (369-C2, 369-C4, 369-B3, and warehouse); fish (tilapia, koi, goldfish, and yellow perch), and soilless medium included; fish without soilless medium included; and lettuce cultivars (Rex, Salanova, and Skyphos).

\begin{tabular}{lrr}
\hline Treatment comparisons & Fresh wt $(\mathrm{g})$ & Dry wt $(\mathrm{g})$ \\
\hline Aquaponic locations by greenhouse & $<0.0001^{* *}$ & $\leq 0.0001^{* *}$ \\
Fish, soilless medium included & $0.0013^{* *}$ & $\leq 0.0001^{* *}$ \\
Fish without soilless medium included & $0.0038^{* *}$ & $0.0003^{* *}$ \\
Cultivar & $0.0026^{* *}$ & $\leq 0.0001^{* *}$ \\
\hline
\end{tabular}

**Indicates $P \leq 0.01$.

Table 2. Mean and SD of fresh and dry weights ( $\mathrm{g}$ ) of total lettuce yield grown in soilless medium, as well as the aquaponic greenhouse and warehouse treatments (floating raft deep water culture; tray ebb and flow; A-frame ebb and flow; tray ebb and flow; and warehouse) and fish types (control/soilless media, perch, goldfish, koi, and tilapia).

\begin{tabular}{llcccc}
\hline Treatment & Fish types & Fresh wt mean & Fresh wt sD & Dry wt mean & Dry wt SD \\
Soilless medium & - & 101.1 & 56.3 & 5.90 & 2.37 \\
Floating raft deepwater culture & Perch & 65.6 & 49.9 & 2.84 & 2.36 \\
Tray ebb and flow & Goldfish & 100.1 & 86.7 & 4.47 & 3.25 \\
A-frame ebb and flow & Koi & 128.7 & 136.8 & 7.32 & 5.90 \\
Tray ebb and flow & Tilapia & 172.3 & 150.4 & 8.16 & 7.20 \\
Warehouse & Koi & 99.4 & 72.0 & 5.12 & 2.88 \\
\hline
\end{tabular}

Table 3. Total mean and SD of fresh weight and dry weight (g) yield of lettuce cultivars Rex, Salanova Series Mix, and Skyphos combined from all aquaponic treatments.

\begin{tabular}{lcccc}
\hline Cultivar & Fresh wt mean & Fresh wt SD & Dry wt mean & Dry wt SD \\
\hline Rex & 94.8 & 71.7 & 6.25 & 4.65 \\
Salanova Series Mix & 103.4 & 129.1 & 5.12 & 5.47 \\
Skyphos & 123.2 & 101.8 & 5.35 & 3.83 \\
\hline
\end{tabular}

Table 4. Reported average wet and dry lettuce weight in grams using aquaponic (all treatments) and hydroponic production methods.

\begin{tabular}{lccccl}
\hline Cultivar & $\begin{array}{c}\text { Wet wt } \\
\text { aquaponic }\end{array}$ & $\begin{array}{c}\text { Wet wt } \\
\text { hydroponic }\end{array}$ & $\begin{array}{c}\text { Dry wt } \\
\text { aquaponic }\end{array}$ & $\begin{array}{c}\text { Dry wt } \\
\text { hydroponic }\end{array}$ & \multicolumn{1}{c}{ Citations } \\
\hline Rex & $45 \mathrm{~g}-21 \mathrm{~g}$ & $118.72 \mathrm{~g}$ & - & $6.41 \mathrm{~g}$ & Buzby, et al., 2016; Sanchez, 2007 \\
Salanova & $89 \mathrm{~g}$ & $91.18 \mathrm{~g}$ & - & - & Søberg, 2016 \\
\hline
\end{tabular}

(5.35 g) or 'Salanova Series Mix' (5.12 g). This indicates that 'Rex' had a higher massto-water ratio in all treatments than the other cultivars.

\section{Discussion}

The average fresh (wet) weight of lettuce from this study was greater than fresh lettuce weights from other aquaponic studies conducted (Tables 3 and 4). 'Rex' had an average fresh weight more than twice as high as the 'Rex' fresh weight from the Buzby et al. (2016) aquaponic study. Although the average wet weight of 'Rex' in this study (94.8 g) did not meet the average wet weight of the hydroponic production (118.72 g; Sanchez, 2007), it was within a comparable range. The average fresh weight of 'Salanova' from this study (103.4 g) was also within the expected range when compared within the average fresh weight of 'Salanova' from both aquaponic $(89 \mathrm{~g})$ and hydroponic production (91.18 g; Søberg, 2016).

According to the University of California Davis, the average fresh weight of a loose-leaf lettuce in field production is $415.79 \mathrm{~g}$ (Takele, 1996). This is significantly more than the average fresh weight of any cultivar from this study or other aquaponic and hydroponic lettuce production studies reviewed. It appears that across studies, the average weight of lettuce produced in an aquaponic or hydroponic production system will be less than half of typical field production.

The type of lettuce (genetics) in production is probably the main reason for reduced fresh harvests in aquaponic production. Production recommendations of leaf lettuce are based around romaine cultivars rather than bibb or heirloom types (Smith et al., 2011). Although romaine-type lettuce is considered loose-leaf by U.S. Department of Agriculture standards, it is not suitable for aquaponic production. The heads are too heavy for the DWC rafts favored by aquaponic growers. Loose-leaf lettuce that has a "bunching" form rather than forming a "head" works better in aquaponic systems but also has less overall mass. When bibb and heirloom cultivars are produced for market, they are significantly smaller and packaged several to a container to reach the higher fresh weight customers expect. For example, the lettuce producer Tanimura \& Antle reported an $85 \mathrm{~g}$ mean head size for their line of artisan lettuce (loose-leaf bunch), packaging four heads to a container (Tanimura \& Antle, 2019).

Although having to package multiple heads together for the consumer retail market is a drawback, there are many advantages aquaponic and other controlled environment production have over field production that make up for the loss. For instance, aquaponics can be much more profitable for production area. Depending on the system used, plant yield per square meter can be as much as five times that of field production in the same season. Aquaponic producers are able to achieve those high yields by using a temporally staggered cropping system and harvesting earlier than field production, as mentioned earlier. Aquaponics also is able to take advantage of extended seasons or even year-round production in some cases, which helps make aquaponic production more competitive by providing fresh produce during the off season.

Loose-leaf bunch and bibb-type lettuce typically grown in aquaponic systems have a much more limited postharvest life than head or romaine lettuce, allowing producers to compete in a different segment of the market. Growing cultivars locally that field producers in California and Arizona are unable to ship long distances provides a competitive advantage to aquaponic producers. They are able to provide produce that is both locally grown, unusual, and even able to be organically certified, all qualities that garner a price premium. That does not yet take into account the revenue generated by the fish production. Consumers are ready and willing to purchase aquaponically grown produce. Short et al. (2018) found consumers' willingness to pay (WTP) did not significantly change when they learned the lettuce was grown aquaponically. In most instances among consumers participating in a Vickrey second-price auction, WTP had similar prices for aquaponic and soil-grown lettuce, averaging $\$ 1.47$ per 8 ounces and $\$ 1.48$ per 8 ounces, respectively (Short et al., 2018). A recent consumer preference study reported that $70 \%$ of consumers are willing to pay more for aquaponically grown produce than soil grown (Abbey, 2018).

Although there was a significant difference between treatments of the fresh weight of lettuce, the differences appear to be among the different types of aquaponic systems and not between the aquaponic systems and the control of soilless medium. When the soilless media control treatment is taken out of the comparison, there is still a significant difference in fresh weight between treatments (Table 1). The difference indicated by the statistical analysis is most likely between the tilapia aquaponic treatment, which had the highest average fresh weight, $172.3 \mathrm{~g}$, and the perch aquaponic treatment, which had the lowest average fresh weight of $65.6 \mathrm{~g}$. The soilless medium control average fresh weight $(101.1 \mathrm{~g})$ was within $1 \mathrm{~g}$ of both the goldfish and warehouse koi treatments (Table 2). It also was higher than the reported average of $85 \mathrm{~g}$ in field production (Tanimura \& Antle, 2019). From this experiment, there is no difference in yield between lettuce produced aquaponically and those grown in soilless medium; however, there is a difference in yield 
between lettuce grown with different aquaponic treatments.

Although this study did not analyze fish yield, based on these findings, aquaponic producers interested in growing lettuce would be advised to consider raising tilapia as the fish component over koi, yellow perch, or goldfish. We also would recommend considering an ebb and flow system over other setups because the two highest average fresh weights occurred in ebb and flow. Considering the cultivars of lettuce tested, 'Skyphos', a loose-leaf bunch type, had the highest average fresh weight with high yield across all systems. Using these findings as a launch point, future studies should consider whether the addition of nutrients to the system might improve yields sufficiently across all treatments.

\section{Literature Cited}

Abbey, M. 2018. Market analysis and productivity of aquaponics in Minnesota. University of Minnesota, St. Paul, M.S. Thesis

Abbey, M., N.O. Anderson, C. Yue, G. Short, M. Schermann, N. Phelps, P. Venturelli, and Z. Vickers. 2019. An analysis of strawberry (Fragaria Xananassa) productivity in northern latitudinal aquaponic growing conditions. J. Amer. Pomol. Soc. 73:22-37.

Anderson, N.O., J. Annis, M. Buchholz, J. Cutting, E. Heuring, E. Jankila, and V. Russell. 2011. Undergraduate sustainable learning: Effects of sustainable soilless media on production and sensory evaluation of cucumbers, basil, parsley, and lettuce. Sustainability 3:1381-1398.

Burpee Seed Co. n.d. The legacy of W. Atlee Burpee. 8 Feb. 2019. <https://www.burpee.com/ gardenadvicecenter/get-to-know/the-legacyof-w.-atlee-burpee/legacy.html>.

Buzby, K.M., N.L. Waterland, K.J. Semmens, and L.-S. Lin. 2016. Evaluating aquaponic crops in a freshwater flow-through fish culture system. Aquaculture 460:15-24.

Cision PR Newswire. Aquaponic farming: Global market intelligence (2011-2020). 2017. 12 Feb. 2018. <https://www.prnewswire.com/ news-releases/aquaponic-farming-global-market-intelligence-2011-2020-300395192.html>.

Costa-Pierce, B.A., J. Rakocy, and W.A. Society. 1997. Tilapia aquaculture in the Americas. World Aquaculture Society; American Tilapia Association, Baton Rouge, LA.

Diver, S. and L. Rinehart. 2006. Aquaponics Integration of Hydroponics with Aquaculture.
ATTRA National Sustainable Agriculture Information Service. 12 Jan. 2019. <https:// attra.ncat.org/attra-pub/summaries/summary. php?pub=56>.

Doležalová, I., A. Lebeda, I. Tiefenbachová, and E. Kř́stková. 2004. Taxonomic reconsideration of some Lactuca spp. germplasm maintained in world genebank collections. Acta Hort. 634:193-201.

Eigenbrod, C. and N. Gruda. 2015. Urban vegetable for food security in cities. A review. Agron. Sustain. Dev. 35(2):483-498.

Hundley, G.C. and R.D. Navarro. 2013. Aquaponics: Integration between aquaculture and hydroponics. Rev. Bras. Agropecuária Sustentável 3:52-61, doi: 10.21206/rbas.v3i2.218.

Kloas, W., R. Groß, D. Baganz, J. Graupner, H Monsees, U. Schmidt, G. Staaks, J. Suhl, M. Tschirner, B. Wittstock, S. Wuertz, A. Zikova, and B. Rennert. 2015. A new concept for aquaponic systems to improve sustainability, increase productivity, and reduce environmental impacts. Aquacult. Environ. Interact. 7:179192, doi: 10.3354/aei00146.

Kuete, V. 2017. Medicinal spices and vegetables from Africa: Therapeutic potential against metabolic, inflammatory, infectious and systemic diseases. Academic Press (Elsevier), Amsterdam.

Lennard, W.A. and B.V. Leonard. 2004. A comparison of reciprocating flow versus constant flow in an integrated, gravel bed, aquaponic test system. Aquacult. Intl. 12:539-553.

Agricultural Marketing Resource Center. 2018. Lettuce. 20 Dec. 2018. <https://www.agmrc.org/ commodities-products/vegetables/lettuce>.

Lewis, W.M. 1978. Use of hydroponics to maintain quality of recirculated water in a fish culture system. Trans. Amer. Fisheries Soc. 107:92-99.

Love, D.C., J.P. Fry, L. Genello, E.S. Hill, J.A Frederick, X. Li, and K. Semmens. 2014. An international survey of aquaponics practitioners. PLoS One 9:102662, doi: 10.1371/ journal.pone.0102662.

Love, D.C., J.P. Fry, X. Li, E.S. Hill, L. Genello, K. Semmens, and R.E. Thompson. 2015. Commercial aquaponics production and profitability: Findings from an international survey. Aquaculture 435:67-74.

Pantanella, E., M. Cardarelli, G. Collab, E. Rea, and A. Marcucci. 2012. Aquaponics vs. hydroponics: Production and quality of lettuce crop. Acta Hort. 927:887-893.

Parr, B., J.K. Bond, and T. Minor. 2018. Vegetables and pulses outlook. 13 Jan. 2019. <https:// downloads.usda.library.cornell.edu/usda-esmis/ files/cj82k729x/5d86p3363/n009w538b/ VGS361.pdf>.
Rakocy, J.E., D.S. Bailey, R.C. Shultz, and J.J. Danaher. 2007. Preliminary evaluation of organic waste from two aquaculture systems as a source of inorganic nutrients for hydroponics. Acta Hort. 742:201-207.

Rakocy, J.E., M.P. Masser, and T.M. Losordo. 2006. Recirculating aquaculture tank production systems: Aquaponics- integrating fish and plant culture. Southern Regional Aquaculture Center Publication 454:16.

Sanchez, S.V. 2007. Master. Universidade Estadual de São Paulo, Brazil.

Short, G., C. Yue, M. Abbey, N.O. Anderson, N. Phelps, P. Venturelli, and Z. Vickers. 2018. Consumer preferences for aquaponic produce: Implications from an experimental auction. Agribusiness 34:742-755.

Smith, R., S. Cruz, and S. Benito. 2011. Leaf lettuce production in California. 13 Jan. 2019. $<$ https://anrcatalog.ucanr.edu/pdf/7216.pdf $>$.

Søberg, E.-E. 2016. The growth and development of lettuce, coriander and swiss chard in a cold water aquaponic system optimized for lettuce production. Master's Thesis, Norwegian University of Life Sciences, Oslo, Norway.

Sorensen, M., L. Robinson, and T. Roth-Krosnoski. 2015. A comparison of rockwool, lava rock, expanded clay aggregate, and coconut coir as growing substrate in a floating raft aquaponic system examining growth rates of 'Improved Amethyst' Basil and 'Nancy' butterhead lettuce. University of Minnesota. 13 Jan. 2019. <http://www.aquaponics.umn. edu/sites/g/files/pua2181/f/substrate-comparison. pdf $>$.

Taiz, L. and E. Zeiger. 2010. Plant physiology. 5th ed. Sinauer Associates, Sunderland, MA.

Takele, E. 1996. University of California cooperative extension production practices and sample costs to produce loose leaf lettuce Coachella Valley Riverside County. 13 Jan. 2019. <https://coststudyfiles.ucdavis.edu/ uploads/cs_public/f4/8a/f48ab159-6c2e-403ab6ce-71eecdeee166/letcoach96.pdf $>$.

Tanimura \& Antle. 2019. Artisan lettuce. 5 Feb. 2019. <http://www.taproduce.com/products/ artisan-lettuce/>.

U.S. Department of Agriculture, National Agricultural Statistics Service. 2017. Crop values 2016 summary. 13 Jan. 2019. <https://www.nass. usda.gov/Publications/Todays_Reports/reports/ cpvl0217.pdf>.

Welbaum, G.E. 2015. Vegetable production and practices. CABI, Oxfordshire, UK. 